\title{
A identidade televisiva como signo
}

Raquel PONTE
Lucy NIEMEYER $^{2}$

RESUMO: A identidade televisiva é a identidade corporativa de um canal de televisão. Composta pelas vinhetas interprogramas, isto é pelas vinhetas transmitidas nos horários comerciais, essa peça do design audiovisual identifica o canal, organiza a programação e, em especial, transmite os valores e as promessas de marca da emissora. Ela visa a criar uma imagem organizacional sólida, gerando uma identificação com o telespectador a fim de garantir o incremento e a fidelização da audiência. Baseado na Semiótica do filósofo americano Charles Sanders Peirce, este artigo busca mostrar a identidade televisiva como um signo complexo, composto de signos sonoros, visuais e verbais. A importância desse estudo é enfatizar que a identidade televisiva comunica valores e significações, utilizando diferentes tipos de signos a fim de aumentar a eficácia da comunicação. Pensamos ser fundamental desenvolver uma pesquisa sistemática a respeito do design audiovisual por seu crescimento como um promissor campo de trabalho e por sua influência na vida cotidiana.

PALAVRAS-CHAVE: Identidade televisiva; Semiótica; Peirce.

\section{Introdução}

Composta pelas vinhetas interprogramas de identidade, também chamadas de vinhetas on-air, transmitidas nos intervalos comerciais, a identidade televisiva é a identidade corporativa de uma emissora de televisão. Essas vinhetas podem ser classificadas em 3 tipos: de identificação, de retenção e assinaturas. As de identificação são aquelas que identificam o canal, comunicando os valores de marca, sem uma função informativa da programação. As de retenção situam o espectador na programação, com o objetivo de reter, como o próprio nome indica, sua audiência. Alguns exemplos: a seguir, voltamos já, ainda hoje. As vinhetas de assinatura utilizam apenas o logo animado da emissora, assinando os programas, e, geralmente, têm menor duração.

A identidade televisiva interessa especialmente à pesquisa acadêmica, por ser uma peça de design de uma área ainda pouco explorada teoricamente, mas fecunda e em franco desenvolvimento em sua prática nas últimas décadas - o design audiovisual -, desenvolvimento este acelerado pela expansão da televisão. A tendência é de ainda maior crescimento do mercado de trabalho dos designers com a convergência das

\footnotetext{
${ }^{1}$ Mestranda em Design pela Escola Superior de Desenho Industrial da Universidade do Estado do Rio de Janeiro ESDI-UERJ.<raquelponte@globo.com>.

2 Doutor em Comunicação e Semiótica - PUC-RJ. Professor Adjunto ESDI/UERJ. Coordenador do LABCULT/UERJ. Integrante do LABSEM/UERJ. < lucy@esdi.uerj.br>.
}

Caderno Seminal Digital Ano 16, nº 13, V. 13 (Jan.- Jun/2010) - ISSN 1806 -9142 
mídias, o que amplia este campo para além da televisão e da internet, em uma nova realidade que comporta outdoors animados, celulares com acesso à grande rede, entre outros objetos portáteis que intensificam a presença do audiovisual no cotidiano.

As vinhetas interprogramas de identidade têm grande importância estratégica para a emissora. Por ser um serviço intangível, a televisão apresenta consequente perecibilidade: a audiência de um programa em determinado horário não pode mais ser aumentada depois de sua transmissão. Tanto na TV aberta quanto na fechada, o zapping é um procedimento comum do espectador. O assinante tem disponível uma gama de emissoras que ele pode ir testando, já que, por ser a televisão um serviço, o consumo ocorre durante a apreciação do programa. A fim de manter o público para uma próxima atração, a identidade televisiva primeiramente cumpre a função de anunciar a programação, de forma a aumentar a curiosidade do espectador. As vinhetas on-air apresentam a grade não só para os que já estão sintonizados na emissora, como para aqueles que, zapeando, acessam o canal durante o intervalo comercial.

Uma outra função da identidade televisiva é resolver o problema do alto grau de intangibilidade inerente aos serviços. Por serem abstratos, há necessidade de usar indícios que legitimem a vantagem de se escolher um ou outro canal. As vinhetas interprogramas de identidade ajudam a criar uma sólida imagem organizacional, se transmitirem adequadamente seus valores e mantiverem uma coerência entre sons, imagens e textos.

Desenvolver lealdade da marca faz com que clientes, que se sentem seguros, não busquem experimentar outros canais de televisão. A satisfação do cliente mantém sua fidelidade à emissora e fidelidade gera hábito de consumo. Ao assistir habitualmente a um canal, o público passa a conhecer a grade de programação, aprendendo a lógica de sua emissora. Isso faz com que seja mais difícil para ele mudar de canal, pois toda mudança envolve um novo custo de aprendizado. A familiaridade contribui para que o consumidor já saiba o que esperar daquela emissora. A falta de conhecimento de um determinado canal torna o espectador perdido, pois ele desconhece o produto que pode ser oferecido, o que aumenta a percepção de risco.

Porém essa lealdade alcançada não decorre apenas do conhecimento do canal, nem da satisfação que o programa pode gerar, nem de uma imagem organizacional sólida. Uma das principais funções da identidade televisiva é veicular significados os quais os consumidores possam compartilhar. Como escreve Bauman (2008, p.24), 
a 'subjetividade' dos consumidores é feita de opções de compra - opções assumidas pelo sujeito e seus potenciais compradores; sua descrição adquire a forma de uma lista de compras. O que se supõe ser as materializações da verdade interior do self é uma idealização dos traços materiais - 'objetificados' - das escolhas do consumidor.

No consumismo das sociedades pós-modernas, o ato de consumir significa o investimento por parte do consumidor na sua própria 'vendabilidade'. Ele deseja incorporar significações veiculadas pelas mercadorias para aumentar sua atratividade, isto é, seu valor social. Segundo Bauman, a próprio indivíduo vira mercadoria. "Tornarse e continuar sendo uma mercadoria vendável é o mais poderoso motivo de preocupação do consumidor, mesmo que em geral latente e quase nunca consciente" (BAUMAN: 2008, p.76). A identidade televisiva expressa nas vinhetas on-air, ao transmitir os valores corporativos, torna-se produto de consumo. Ao assistir determinado canal de televisão, por exemplo, o telespectador evidencia sua identidade perante a sociedade.

Compreendendo que a identidade televisiva resulta da articulação de sons, imagens e textos, a teoria norteadora deste artigo é a semiótica peirciana, que melhor explicita e analisa a natureza dos signos de um meio que carrega em si múltiplas linguagens.

\section{Semiótica Peirciana e matrizes da linguagem e pensamento}

Para Peirce, signo "[...] é aquilo que representa algo para alguém em algum aspecto ou modo. Ele se endereça a alguém, isto é, cria na mente [...] um signo equivalente ou, talvez, mais desenvolvido, ${ }^{3 \prime \prime}(C P, 2.228)$. Pautando-nos nas categorias da Fenomenologia peirciana, podemos compreendê-lo como um primeiro lógico que medeia a relação entre um objeto - um segundo que é representado - e uma mente interpretadora, gerando um terceiro: um interpretante. Do ponto de vista real, porém, é o objeto que tem primazia e por isso determina o signo.

Visto que o signo não representa o objeto em todos os sentidos, pois de outra forma ele seria o próprio objeto e não o signo, ele promove uma visão parcial deste segundo correlato. Sendo assim, quanto mais signos puderem ser coadunados em um

\footnotetext{
3 " [...] is something which stands to somebody for something in some respect or capacity. It addresses somebody, that is, creates in the mind [...] an equivalent sign, or perhaps a more developed sign" [tradução livre da autora].
}

Caderno Seminal Digital Ano 16, nº 13, V. 13 (Jan.- Jun/2010) - ISSN 1806 -9142 
signo mais complexo (SANTAELLA: 2005, p.279), a fim de reforçar a referência ao mesmo objeto, mais aspectos do objeto poderão ser apresentados. O uso de uma mistura de signos diferenciados amplia a compreensão do objeto, desde que todos, de forma coerente, remetam a ele.

Importante frisar que Peirce tinha uma visão ampliada do signo e por isso um gesto, uma palavra, uma cor, um sentimento, um pensamento, tudo isso constitui signo, isto é, representa alguma coisa para uma mente. Por esse motivo, a semiótica peirciana tanto contribui para análise do meio televisivo, por ser ele composto não apenas pela linguagem verbal, mas também por sons e imagens em movimento.

Baseada nas categorias fenomenológicas de Peirce e em sua semiótica, Lucia Santaella propôs uma divisão tripartite das matrizes da linguagem e pensamento. Ela concluiu que, se não há pensamento sem signos, este deve seguir a mesma lógica organizativa. A denominação proposta por Santaella decorre do fato de a autora relacionar de forma indissociável a linguagem e o pensamento.

Qualquer coisa que esteja à mente, seja ela de uma natureza similar a frases verbais, a imagens, a diagramas de relações de quaisquer espécies, a reações ou a sentimentos, isso deve ser considerado como pensamento (SANTAELLA: 2005 p.55).

Logo os signos estão intrinsecamente ligados ao pensamento, sendo imprescindíveis para que este ocorra. Do mesmo modo, mostra-se impossível uma linguagem independente da semiose. A linguagem manifesta-se, exteriorizando-se e materializando-se nas criações humanas. Vale destacar que Santaella escolheu o termo matriz por entendê-lo como lugar onde algo se gera ou se cria, uma vez que ela pretendia classificar as linguagens e pensamentos originais, mais essenciais, de onde todas as outras linguagens se originam. Assim como as categorias de Peirce buscavam dar conta de explicar a multiplicidade dos fenômenos, as matrizes objetivam explicitar a origem das múltiplas linguagens existentes, denominadas como híbridas, por ser uma mescla das três matrizes primordiais.

Santaella elegeu três linguagens como as matrizes para todas as demais existentes: a sonora, a visual e a verbal. A primeira decorre do sentido da audição; a segunda, da visão; e a terceira, da faculdade de verbalização própria do homem. A autora afirma que apenas a visão e a audição, como sentidos da percepção humana, criam linguagens, diferentemente do tato, do paladar e do olfato. Para ser entendida como tal, a linguagem deve ter os seguintes atributos: organização hierárquica e 
sistematicidade, metalinguagem (deve ser autoreferente) e recursividade (deve ser passível de registro, mesmo que apenas da memória). Esse último atributo mostra que apenas podemos lembrar, revivenciando a sensação, do sonoro e do visual. Podemos visualizar um quadro ou cantarolar uma música mentalmente, mas não conseguimos sentir novamente o sabor de uma maçã ou o aroma de uma rosa, imaginando o gosto ou o cheiro. $\mathrm{O}$ tato seria o que mais se aproxima de uma quase-linguagem, porém podemos entender que "os processos perceptivos que não fazem linguagens, porque são mais moventes, sutis e viscerais, encontram moradas transitórias nas linguagens do som, da visão e do verbal" (SANTAELLA: 2005 p.78).

Assim como a semiótica peirciana tem uma concepção abstrata de signo, que pode ser aplicada a qualquer forma pela qual ele se apresente, seja verbal, visual, sonora, olfativa, gustativa ou tátil, Santaella propõe que entendamos cada uma dessas matrizes em suas especificidades próprias, sem tentar compreender determinada linguagem segundo as características de outra. Ela estabelece, então, o que é próprio de cada matriz: na sonora, a sintaxe (combinação dos elementos a fim de formar unidades mais complexas); na visual, a forma (aspecto exterior dos corpos materiais); e na verbal, o discurso (organização da sequencialidade discursiva). A autora mostra também que a forma incorpora a sintaxe, assim como o discurso presume a forma e a sintaxe.

A primeira matriz, a sonora, compreende todo e qualquer tipo de som. Tem como eixo fundamental a sintaxe $($ syn $=$ junto/com, taxis $=$ arranjo), pois combinam sons, alturas, durações etc. para formar elementos mais complexos. Apresenta dominância do signo icônico por apresentar atributos como fugacidade, evanescência e indeterminação, e por o ícone caracterizar-se pela baixa referencialidade ao objeto. Assim é o som: qualidade pura, imediata, de grande poder evocador.

A segunda matriz de linguagem e pensamento abrange as formas visuais fixas, isto é, as imagens que não possuem tempo intrínseco, pois o tempo inscreve-se na matriz sonora, enquanto o espaço, na matriz visual. Deste modo, as imagens em movimento seriam uma linguagem híbrida, aliando visualidade a sonoridade. Santaella explicita, também seguindo esse raciocínio, que as esculturas pertencem a essa matriz quando têm um caráter eminentemente visual, não apelando para o sentido tátil. Já os objetos utilitários tridimensionais, por se adequarem ao uso humano, colocando muita ênfase na ergonomia, não participam desse grupo. 
A segunda matriz, a visual, apresenta dominância do índice, o que, a princípio, pode soar estranho, visto que a imagem muitas vezes foi associada ao signo icônico. Porém Santaella argumenta que a característica do ícone é a grande ênfase no representâmen e que a semelhança demonstra uma fusão entre o objeto e o signo. $\mathrm{O}$ índice, de outro lado, refere-se a ou aponta para o objeto, destacando-o, seja por uma conexão física, seja apenas como referência. As formas visuais fixas, em sua grande maioria, fazem esse movimento de indicar seu objeto e por isso caracterizam-se como índices. Vale lembrar que, seguindo a lógica das categorias que presumem sempre as anteriores, "todo índice tem um ícone embutido" (SANTAELLA: 2005, p.199).

A terceira e última matriz corresponde à linguagem verbal escrita, uma vez que a oral incorpora elementos da sonoridade e do gestual, sendo assim considerada híbrida por Santaella. Destacam-se como principais características do signo linguístico a arbitrariedade e a convencionalidade. É uma lei que o fará ser interpretado como se referindo a um determinado objeto, que, nesta matriz, se caracteriza por ser uma ideia, um conceito, um elemento abstrato.

\section{A identidade televisiva como signo}

Podemos perceber que a identidade televisiva pode ser compreendida como um signo, uma vez que ela representa os valores de marca de um canal de televisão - seu objeto. Ela medeia a relação dos telespectadores com o conceito da emissora, que, por também constituir um signo, torna esse processo semiótico uma semiose genuína.

Indo além as vinhetas interprograma podem ser vistas como um signo mais complexo, pois combinam signos sonoros, visuais e verbais, isto é, signos pertencentes às três matrizes de linguagem e pensamento definidas por Santaella.

\subsection{Signos sonoros}

Segundo Ràfols e Colomer (2006, p.34), o som compreende a música, a palavra falada e os efeitos sonoros (sonoplastias). Diferentemente da palavra falada, em que precisamos conhecer o código linguístico para interpretarmos o signo, a música é uma linguagem convencional que pode ser apreciada independentemente do conhecimento técnico de seus termos e de sua estrutura. "O dado curioso da música é que a compreendemos e reagimos a ela, mesmo sem ter que aprendê-la" (ACKERMAN:

Caderno Seminal Digital Ano 16, nº 13, V. 13 (Jan.- Jun/2010) - ISSN 1806 -9142 
1992, p.248). Isto decorre do fato de, na matriz sonora, o aspecto qualitativo predominar ao convencional. Por suas amplas possibilidades de interpretação, "o universo sonoro é o âmbito no qual se produz a comunicação das sensações mais primárias, essenciais e dificilmente racionalizáveis que o ser humano é capaz de expressar e perceber" (RODRÍGUEZ: 2006, p.16). Desta forma, é possível emocionar-se com uma canção sem ser músico.

Por convenções culturais, associam-se tons maiores a alegria e menores a sentimentos de tristeza e melancolia. Relacionam-se movimentos ascendentes na melodia a leveza, ao subir as alturas para notas mais agudas. De forma oposta, movimentos descendentes na escala, rumo aos tons mais graves, são interpretados com maior peso. Já no caso dos andamentos, a velocidade do pulso que marca uma música, acredita-se que a associação de pulsos mais rápidos como o allegro à alegria - como o próprio nome em italiano já demonstra -, esteja não apenas relacionada a questões culturais, mas a motivos biológicos. A velocidade do batimento cardíaco médio humano é de 60 a 80 batidas por minuto. Logo, andamentos mais velozes que este padrão são relacionados com estados de excitação, como o vivace (152-168 bmp), enquanto aqueles mais lentos, com estado de pesar ou cansaço, como o grave (40 bpm). Um som de maior intensidade traduz-se por força, enquanto um de menor intensidade, por suavidade. Um ataque e uma queda mais fortes - início e fim, respectivamente, do contorno sonoro, que são "[...] todas as evoluções da intensidade e do tom que se produzem ao longo de um evento sonoro concreto" (RODRÍGUEZ: 2006, p.215) - sugerem maior dinamismo e contundência.

Vale mencionar em particular os timbres dos instrumentos e os estilos musicais que carregam em si significações relacionadas com sua história. Um som de violino, por exemplo, remete o ouvinte a um determinado estilo musical e a um contexto de audição totalmente diferente do que uma guitarra faria. Um samba leva em seu ritmo e instrumentos toda a carga emocional de seu surgimento, do seu público, da sua evolução, do seu gestual, da sua indumentária, da sua localidade, de forma diversa de um forró, de um rock, de um maracatu, de uma música dodecafônica etc.

As convenções culturais no âmbito sonoro também se estendem à palavra falada e aos efeitos sonoros. Os timbres das vozes de locutores transmitem sentimentos distintos da eventual imagem dos mesmos - como ocorre no filme "Cantando na Chuva", de 1952, no qual se mostra o problema vivido por uma atriz protagonista com o 
advento do cinema sonoro, ao perceber que sua voz esganiçada não condiz com sua imagem. Assim, uma voz masculina grave e pausada normalmente é associada a maior sobriedade que uma voz infantil, devido a todas as possibilidades de interpretação relacionadas aos conceitos de criança, adulto, homem, mulher etc, variáveis de acordo com os papéis que representam em uma sociedade.

Normalmente, nos efeitos sonoros, há grande relação referencial entre som e fonte sonora, pois a sonoplastia busca reviver esse elo entre imagem e som. Em projetos mais simples, busca-se recriar um som de pássaro para representar a ave, assim como se grava o som de vidro quebrando para melhor apresentar um vidro partindo-se. Porém, com as possibilidades abertas pela música concreta e eletrônica e o processo de acusmatização,

[...] nós nos encontramos não só com a possibilidade de ouvir os sons neles mesmos, livres de sua conexão causal original e fatiálos em novas combinações antes impossíveis (Música Concreta), mas também [...] de reassociar estes sons com imagens de objetos e situações diferentes, à vezes, surpreendentemente diferentes dos objetos e situações que geraram os sons originariamente (MURCH apud CHION, 1994, p.XVI) ${ }^{4}$.

Assim, os diversos tipos de sons que podem manifestar-se na identidade televisiva associam-se entre si ou com as demais matrizes, de forma convencionada ou inesperada, a fim de aumentar a eficácia interpretativa de uma vinheta. Podemos destacar na palavra falada alguns tipos de signos que veiculam significações: o timbre da voz do locutor, a cadência da fala, a intensidade, a respiração do falante, o sotaque e a própria língua do discurso, que já se situa em uma região fronteiriça com a matriz verbal. Nos efeitos sonoros, podemos sublinhar a intensidade do som, a força do ataque, o timbre, a altura, entre outros. Nas músicas, transmitem significações o timbre, a intensidade, a altura, o ataque, a queda, o andamento, a tonalidade, os instrumentos, o ritmo, a duração etc.

Cada um desses signos da palavra falada, dos efeitos sonoros e das músicas deve ser analisado separadamente e em grupo, sempre tendo em conta todo o processo semiótico e o contexto da mensagem. Portanto, qualquer análise semiótica deve

\footnotetext{
4 “[...] we found ourselves able to not only listen to the sounds themselves, liberated from their original causal connection, and to layer them in new, formerly impossible combinations (Musique Concrète) but also [...] to reassociate these sounds with images of objects or situation that were different, sometimes astonishingly different, than the objects or situations that gave birth to the sounds in the first place" (MURCH apud CHION, 1994, p.XVI) [tradução livre da autora].
}

Caderno Seminal Digital Ano 16, nº 13, V. 13 (Jan.- Jun/2010) - ISSN 1806 -9142 
considerar, para a compreensão do papel de um signo, o contexto e o destinatário da mensagem e não simplesmente um som desconectado de um processo maior que relaciona também outros dois tipos de signos: visuais e verbais.

\subsection{Signos visuais}

A identidade televisiva, por estar em um meio que consegue incorporar diversas linguagens para dentro dele, pode abarcar ilustrações, pinturas, imagens filmadas, infografias totalmente geradas por computador, entre outras possibilidades de formas. Segundo Santaella (2005), as formas não-representativas são as imagens abstratas e têm baixa referencialidade com o seu objeto. As figurativas (pinturas realistas, fotografias etc) têm mais conexão com ele e as representativas (símbolos matemáticos, químicos etc) são altamente convencionais. Portanto, quanto menos referencial, maiores as possibilidades de interpretação que a imagem pode gerar. Quanto mais convencional, menor a amplitude interpretativa. A escolha entre por um determinado tipo de imagem nas vinhetas se dará de acordo com a mensagem que a emissora deseja transmitir e com o público com o qual deseja se comunicar.

Toda imagem pode ser decomposta em elementos primordiais que a compõem: a forma, que é a chave para a compreensão da matriz visual; a linha, "[...] o articulador fluido e incansável da forma [...]" (DONDIS: 2007, p.23), composta de pontos; a direção; o movimento; a textura, a escala; a dimensão; e a cor.

O movimento é um dos elementos principais na imagem audiovisual. O ser humano é um animal eminentemente visual. Desde o início da humanidade, ainda na Pré-História, o homem conseguiu eternizar imagens fixas em suportes. Bizões foram pintados em paredes, mãos foram usadas como carimbo nas cavernas. Ao longo do tempo, as técnicas foram evoluindo e os tipos de suportes foram sendo ampliados. Porém o movimento presenciado no cotidiano podia apenas ser sugerido em imagens estáticas. As primeiras invenções ópticas que simulam o movimento remontam ao século XVII. Mas só no na virada do século XIX para o XX, baseado no fenômeno da persistência retínica, que o movimento pôde ser simulado tanto com o advento do cinema quanto com o da televisão.

Mesmo em uma imagem fixa, porém, o movimento é sempre um elemento presente. O borrão que um objeto deixou em uma fotografia é um indício de sua passagem, enquanto a hierarquização das figuras em uma composição induz a um

Caderno Seminal Digital Ano 16, nº 13, V. 13 (Jan.- Jun/2010) - ISSN 1806 -9142 
movimento. Esse elemento confere dinamismo à peça e a televisão, que veicula imagens não-fixas, sabe bem explorar seu potencial comunicativo.

Além desses elementos básicos, não podemos deixar de frisar que há outra questão a ser considerada ao se analisar uma imagem: as relações entre os elementos. A harmonia e o contraste, citados por Dondis (2007, p.24), podem se apresentar pelo equilíbrio ou pela instabilidade, pela simetria ou assimetria, pela irregularidade ou pela regularidade dos elementos constituintes. Também devemos considerar, fora os elementos e suas relações, o estilo, pois assim como um ritmo musical ou seus instrumentos na matriz sonora trazem em si significações relacionadas à sua história, ao seu uso, aos seus costumes etc, o estilo visual carrega também grandes possibilidades interpretativas. Uma vinheta que carregue um estilo grunge, como as primeiras veiculadas pelo canal americano MTV na década de 1980, comunica visualmente uma intenção totalmente diferente das vinhetas tecnológicas e futuristas da emissora brasileira Rede Globo.

\subsection{Signos verbais}

Os signos verbais estão presentes nas vinhetas on-air principalmente em três momentos: no logotipo ou assinatura visual da emissora, nas chamadas - voltamos a apresentar, a seguir, ainda hoje etc -, e nos nomes dos programas nas vinhetas de retenção. Por se tratar de signo convencionado, as palavras só são passíveis de serem interpretadas por aqueles que dominam seu código. Desta forma, as informações transmitidas por um canal por assinatura americano em sua identidade televisiva só poderão ser decodificados pelos espectadores familiares à língua inglesa.

O verbal, nas vinhetas de identidade, dificilmente não se mesclará com a sonora e a visual. A palavra falada, na locução ou na música, já é considerada por Santaella como linguagem híbrida, pois incorpora a sonoridade. Da mesma forma, o tratamento gráfico que é dado aos textos nas vinhetas e ao nome da empresa nos logotipos também inscreve a visualidade na matriz verbal, por se tornar impossível desvincular uma da outra e pelo fato de a matriz visual acrescentar significações à verbal.

Além disso, o que é característico do verbal, segundo Santaella (2005) é o discurso. Ora, se a temporalidade e a sintaxe são próprias da sonoridade, mas podem perpassar pela visualidade e pelo verbal; se a espacialidade e a forma são essências do visual, mas transparecem também no som e no discurso; também a organização 
sequencial da matriz verbal pode aparecer no mundo sonoro e visual. $\mathrm{O}$ desenvolvimento de uma peça musical nas suas idas e vindas, mesmo não utilizando o código linguístico, está impregnado da estruturação básica do discurso. Uma animação apenas de imagens na qual se desenrola uma ação está prenhe de narrativa. Portanto não devemos apenas fixar-nos na palavra arbitrária na identidade televisiva, mas também na estruturação discursiva que ela apresenta.

\subsection{Relação entre os signos}

As linguagens que mesclam as três matrizes de linguagem e pensamento e que predominam no mundo em detrimento das linguagens puramente sonoras, visuais e verbais são consideradas híbridas por Santaella. Isto decorre do fato de que "[...] as matrizes da linguagem e pensamento estão alicerçadas nos processos perceptivos, o que significa que uma dinâmica similar à dos sentidos [da sinestesia] é desempenhada nas interações e sobreposições das linguagens" (SANTAELLA: 2005 p.78). Elas podem surgir da mistura de duas matrizes (sonora-visual, sonora-verbal, visual-verbal), ou da combinação das três (sonora-visual-verbal), como, por exemplo, o cinema e o vídeo.

Santaella (2005, p.388) escreveu que entre esses múltiplos canais semióticos, a televisão é aquela que leva a multiplicidade ao limite de suas possibilidades. Isto ocorre porque ela, por sua própria constituição, é capaz de absorver para dentro de si quaisquer outras linguagens: rádio, teatro, cinema, shows, publicidade, jornalismo etc. Certamente, ao serem absorvidas dentro da linguagem específica que é a televisão, essas linguagens mudam, por vezes, de forma bastante radical. Isso, entretanto, não modifica a natureza da linguagem da televisão em si que é, justamente, feita dessas absorções e misturas, em uma sintaxe que lhe é muito particular.

\subsubsection{Verbal e suas relações com o visual e o sonoro}

Segundo Rodríguez, desde que começamos a aprender a linguagem verbal arbitrária, ela se converte na principal forma de apreensão do mundo.

Conforme o processo de aprendizagem de uma pessoa evolui, as linguagens arbitrárias adquirem uma prioridade extraordinária sobre todos os níveis de reconhecimento sonoro. 
[...] a partir do momento em que aprendemos a falar, tem início para nós uma etapa de formação [...], que está baseada de modo muito prioritário pelas formas sonoras e escritas da fala [...]. A partir de então, tudo o que nos rodeia será sempre nomeado, explicado, interpretado, organizado, estudado, classificado, aceito, recusado, narrado, armazenado... pela linguagem arbitrária mais hegemônica e imperialista que existe: a língua (RODRÍGUEZ; 2006, p.334).

Atualmente, porém, com o desenvolvimento dos meios audiovisuais e o constante crescimento do uso maciço de imagens em diversos suportes, podemos dizer que as duas matrizes alcançaram grande importância comunicativa para o homem. Além disso, a materialização da abstração do verbal em signos sonoros (fala) e visuais (escrita) faz com que as três matrizes estejam cada vez mais imbricadas. Portanto devemos ver como elas se relacionam, como elas se reforçam ou se contradizem em cada peça de design.

$\mathrm{Na}$ identidade televisiva, o texto normalmente tem uma função informativa. Nas assinaturas e nas vinhetas de retenção, que finalizam com a assinatura do canal, os signos verbais buscam comunicar o nome do canal a que estamos assistindo. No caso das vinhetas de retenção, eles visam anunciar elementos da programação, organizando a grade da emissora e mantendo o espectador sintonizado na atração. Desta maneira, o verbal, que tem enorme importância na televisão, a ponto de ela ser considerada um rádio ilustrado - isto é, o verbal concretizado em signos sonoros e verbais aliado a imagens -, mantém seu papel na identidade televisiva, principalmente nas vinhetas de retenção.

Existem muitas variações no design das vinhetas decorrentes da intenção comunicativa da emissora, mas podemos destacar um padrão mais adotado: o uso de uma locução que narra a programação, enquanto aparecem imagens do programa citado.

Os canais de televisão sabem que os comerciais são um grande momento de dispersão para o espectador, que irá até mesmo sair do recinto em que se encontra a televisão, a fim de resolver outros afazeres enquanto a programação não retorna. A locução do texto, que pode também ser visualizado na tela, pode ser escutado mesmo pelo público que esteja a alguns metros do aparelho. Desta maneira, o verbal sonoro cumpre o papel de chamar a audiência para o canal, sinalizando a programação. Outros canais, porém, projetam peças diferentes desse padrão, utilizando o verbal escrito, sem locução, sem referência a nenhuma imagem do programa anunciado. 
Podemos ver que são muitas as possibilidades de relação do verbal com o visual passíveis que podem ser exploradas. Tudo depende do objetivo que a emissora traça para uma determinada vinheta, dentro de um contexto mais amplo, que considera o público-alvo, os valores do canal e a coerência dela com toda a identidade televisiva.

Em um estudo mais específico das relações entre imagem e texto, Santaella e Nöth (2005, p.54-55) sintetizam três possibilidades de relação entre visual e verbal: de redundância, de informatividade e de complementaridade. Na redundância, a imagem é considerada inferior ao texto, isto é, o texto tem maior função comunicativa, sendo a imagem uma mera ilustração que não acrescenta informação adicional a ele. Na relação de informatividade, ocorre o contrário: a imagem é superior ao texto, dominando-o. Este é o caso de uma foto com uma legenda, quando o texto também não aumenta o potencial de significação da imagem. O último caso é da complementaridade, quando há uma equivalência na função comunicativa de texto e imagem.

A identidade televisiva tem ora predominância de signos verbais, ora, de signos visuais. Não há uma regra pré-definida, portanto podemos encontrar vinhetas em que uma das matrizes tem mais peso que a outra, ou momentos das vinhetas em que há dominância de um sobre o outro. Porém, percebemos que a tendência no meio é a da complementaridade entre as matrizes, o que só pode contribuir para o aumento da eficácia da comunicação.

A vantagem da complementaridade do texto com a imagem é especialmente observada no caso em que conteúdos de imagem e de palavra utilizam os variados potenciais de expressão semióticos de ambas as mídias (SANTAELLA \& NÖTH: 2005, p.55).

Por fim, além do verbal materializado em palavras, devemos novamente atentar para o fato de que o discurso, chave para a compreensão da terceira matriz da linguagem e pensamento, perpassa o visual e o sonoro, como abordado anteriormente. Tanto a evolução de uma forma musical quanto de uma sequencia de imagens trazem em si um discurso. Como diz Chion a respeito do cinema e que pode ser estendido à televisão visto incorporar ela muitos dos seus elementos constituintes -, a linguagem está presente na forma como as imagens são concebidas, filmadas e editadas para se constituir em um discurso. E uma tomada - um take - ou um gesto podem ser analogamente entendidos como palavras que compõem um todo maior. 


\subsubsection{Oaudiovisual}

A relação entre imagem e som na televisão não poderia ser ignorada, por ser este um meio audiovisual, em que há uma paridade de importância entre essas duas bandas. Enquanto o cinema, mesmo sendo audiovisual, tem na imagem a chave para sua existência - podemos conceber um filme mudo, mas não podemos entender como cinema, uma trilha sonora sem imagens -, a televisão surgiu, principalmente no Brasil, do rádio, de forma que o som atinge a mesma importância que a imagem. Assim,

[...] no design audiovisual, os sons estão associados e coordenados com as imagens, e esta convergência de sensações terá um efeito multiplicador, de forma que o som e a imagem passarão a formar parte de uma unidade de significação5 (RÀFOLS \& COLOMER: 2006, p.16).

A grande interação entre essas duas matrizes, a composição de som e imagem como uma unidade em vez de partes separadas, decorre da necessidade de coerência que nosso sistema perceptivo busca estabelecer entre as diversas percepções simultâneas. Isto porque os sentidos nunca atuam isoladamente: a audição, a visão, o tato, o olfato, as sensações motoras, entre outras, percebem os estímulos externos ao mesmo tempo. "Não só vemos um automóvel que se aproxima, como também escutamos seu motor e o ruído de seus pneus rodando, sentimos o cheiro de gasolina queimada, percebemos que o ruído se torna cada vez mais intenso e mais preciso" (RODRÍGUEZ: 2006, p.263). Essa simultaneidade foi fator primordial na evolução animal, que permitiu uma melhor adaptabilidade do ser no mundo, garantindo maior possibilidade de perpetuação das espécies. Perceber, por meio de todos os sentidos possíveis, sinais de risco e perigo, bem como proximidade de alimentos, garante a sobrevivência de um grupo.

Essa característica fisiológica promove a percepção do fenômeno de sincronia audiovisual. Ela ocorre quando há uma coincidência no tempo entre dadas oscilações acústicas e determinadas mudanças visuais. Como nosso organismo, ao longo dos anos de aprendizado perceptivo, aprendeu que uma alteração na fonte sonora está atrelada à variação do som, há uma imediata associação entre som e objeto quando há sincronia, mesmo que o objeto não seja naturalmente sua fonte sonora. Por exemplo, em um filme de ficção científica, associamos o som de tiros a laser com o brilho que sai da arma

\footnotetext{
5 “[...] en el diseño audiovisual los sonidos están asociados y coordinados con unas imágenes, y que esta convergencia de sensaciones tendrá un efecto multiplicador, de manera que sonido e imagen pasarán a formar parte de una unidad de significación" [tradução livre da autora].
}

Caderno Seminal Digital Ano 16, nº 13, V. 13 (Jan.- Jun/2010) - ISSN 1806 -9142 
quando estes ocorrem simultaneamente. Ainda que não exista, no mundo compartilhado, o som de um revólver a laser por ser ele inexistente, o som criado pelos sonoplastas para representá-lo é automaticamente interpretado como derivado daquela fonte sonora. Isto porque “[...] é altamente improvável que o início e o final de um fenômeno sonoro coincidam exatamente no tempo com o início e o final de um fenômeno visual; somente por coincidência” (RODRÍGUEZ: 2006, p.318).

A sincronia é um fenômeno que destaca tanto a imagem quanto o som quando ocorrem de forma simultânea. Em uma imagem em movimento, com uma série de elementos em ação, geralmente haveria uma tendência de nossa visão em selecionar aqueles de dimensões maiores ou os que ocorrem em um primeiro plano. Ao associar, porém, um desses elementos, entre os vários pontos de atenção de uma imagem, a um som, sublinha-se essa figura. Mesmo um ponto diminuto no plano de fundo tem seu efeito destacado se sincronizado com um som. Da mesma forma, em uma composição de efeitos sonoros ou em uma música, em que vários sons diferentes ocorrem no tempo, prestaremos mais atenção a um específico se em sincronia com uma imagem.

Existem grandes diferenças entre as percepções visual e sonora. Enquanto a audição nos faz reconhecer o ambiente mais próximo, a visão nos ajuda a perceber também o espaço que está longe de nós. Ela alterna, num espaço curtíssimo de tempo, o ambiente imediato e o distante e, por essa mudança constante, é mais instável no tempo que a audição. Esta nunca pode deixar de atuar, mesmo conscientemente, pois não temos pálpebras para os ouvidos. Além de podermos escolher não ver - ao fecharmos nossos olhos -, a visão tem uma percepção enquadrada. No caso humano, a localização frontal dos olhos faz com que ganhemos em profundidade, mas percamos em ângulo. $\mathrm{O}$ som, por seu turno, é omnidirecional. Talvez, por essas características, o som impacte tanto nos sentimentos, pois representa a percepção daquilo que se encontra mais próximo do ouvinte, podendo situar-se até mesmo atrás dele, e é o único sentido que nunca pára de atuar completamente.

[...] Basicamente o ouvido analisa, processa e sintetiza mais rápido que os olhos ${ }^{6}[\ldots]$

Tome um rápido movimento visual - um gesto com a mão - e o compare com uma trajetória abrupta de som com a mesma duração. $\mathrm{O}$ rápido movimento visual não formará uma imagem distinta, sua trajetória não será memorizada em uma figura precisa. Já uma trajetória sonora de mesma duração terá sucesso

\footnotetext{
6 “[...] basically, the ear analyzes, processes, and synthesizes faster than the eye" [tradução livre da autora].
} 
em ter uma forma definida, individual, reconhecível e distinta das demais.

Isto não é uma questão de atenção. Nós podemos ver, atentamente, uma tomada de um movimento visual dez vezes (como, por exemplo, um personagem fazendo um complicado gestual com o braço), e ainda não seremos capazes de discernir seus contornos claramente. Ouça dez vezes uma rápida sequência de som e sua percepção a confirmará com cada vez mais precisão ${ }^{7}$ (CHION, 1994, p.10).

Por isso, o som atua constantemente como unificador de sequências visuais diferentes, justapostas na edição, organizando a narrativa. Com um som incorporado, uma sequência de imagens que sofre uma edição mais fragmentada pode ser melhor compreendida como unidade de significação que uma sem áudio. E ele também tem como função fixar melhor um estímulo na memória, por ser mais rapidamente processado e por acentuar a carga emotiva na comunicação.

A audição relaciona-se mais com a temporalidade, enquanto a visão, com a espacialidade. Interessante notar é que, ao longo do século $\mathrm{XX}$, com o afastamento da pintura da representação ocidental tradicional da realidade, iniciado pelas vanguardas européias, as formas visuais têm se aproximado mais da lógica da sonoridade. Com a culminância do abstracionismo, vemos que a imagem liberta-se da referencialidade, em sua busca pela qualidade pura. Não é por coincidência que uma sociedade que caminhou para a fugacidade, a instabilidade e a liquidez da pós-modernidade buscou novas formas de expressão que destacaram o fugidio do tempo nas formas visuais. Veremos, a seguir, como o tempo está cada vez mais presente em todas as matrizes.

\subsubsection{Tempo no som, na imagem e no discurso}

Uma das principais características da televisão é reproduzir imagem em movimento. A imagem em movimento já constitui-se como uma forma híbrida, diferentemente das formas fixas, pois insere, na visualidade - mais relacionada ao espaço -, o tempo - referente à matriz sonora.

\footnotetext{
7 "Take a rapid visual movement - a hand gesture - and compare it to a abrupt sound trajectory of the same duration. The fast visual movement will not form a distinct figure, its trajectory will not enter the memory in a precise picture. In the same length of time the sound trajectory will succeed in outlining a clear and definite form, individuated, recognizable, distinguishable from others.

This is not a matter of attention. We might watch the shot of visual movement ten times attentively (say, a character making a complicated arm gesture), and still not be able to discern its line clearly. Listen teen times to the rapid sound sequence, and your perception of it will be confirmed with more and more precision" [tradução livre da autora].
} 
A questão do tempo na imagem foi pensada de forma diferente por autores diversos. Jacques Aumont propôs uma divisão entre as imagens não-temporalizadas, aquelas que são idênticas a si próprias no tempo, e as temporalizadas, que se modificam no fluxo temporal pelo efeito do dispositivo que as reproduz sem a intervenção do espectador. Para ele, as imagens temporalizadas seriam as imagens em movimento, como o cinema, a televisão, a animação etc.

Santaella e Nöth discordam de tal classificação, que relaciona inseparavelmente tempo a movimento. Para os autores, imagens fixas também são impregnadas de tempo, ainda que de forma diferente. Eles então propõem (2005, p.75) duas grandes divisões: tempo intrínseco, semelhante à concepção de imagem temporalizada de Aumont, só que sem se restringir à questão do dispositivo, e tempo extrínseco, que são as formas de temporalidade externas à imagem.

No primeiro grupo, há três grandes divisões. O primeiro é o tempo do dispositivo ou suporte; o segundo, o tempo da fatura ou enunciação, que pode ser compreendido como o "[...] nível que corresponderia a algo semelhante àquilo que nas teorias linguísticas e teorias do discurso costuma ser chamado de tempo da enunciação" (SANTAELLA \& NÖTH: 2005, p.75); e o terceiro, tempo dos esquemas e estilos “[...] que dizem respeito a caracteres internos das imagens" (idem: 2005, p.75).

Já o segundo grupo comporta o tempo de desgaste - o envelhecimento e deteriorização do suporte da imagem, por isso externo a ela -, o tempo do referente ou enunciado - também chamado de tempo representado -, e a ausência de tempo, que ocorre nas imagens abstratas não-figurativas.

Por tal classificação, as imagens em movimento veiculadas pelo meio televisivo não possuem tempo extrínseco de desgaste, por serem elas estocadas em meio digital, fazendo com que o tempo externo não aja sobre seu suporte. Mas sua principal característica é possuir tempo intrínseco, devido ao dispositivo eletrônico que as reproduz: a televisão projeta quadros sequencialmente, por um sistema de varredura, que substitui a imagem anterior numa velocidade tal que permite que nossa visão entenda a sucessão de imagens diferentes como uma única imagem desenvolvendo-se em um fluxo temporal. As imagens em movimento já se configuram, desta forma, como uma mistura entre as matrizes visual e sonora, congregando espaço e tempo.

No design audiovisual, assim como no cinema e na animação, portanto, o tempo, ainda que tenha grande conexão com a sonoridade, pode ser captado também pela 
percepção visual. Como diz Krasner (2004, p.151), “[...] o ritmo é percebido tanto pelos olhos quanto pelos ouvidos ${ }^{8}$.

Os movimentos de câmeras - panorâmicas, quando a câmera se move sobre o próprio eixo, e travellings, quando ela se move sobre um caminho - ou suas simulações por programas de computador, e a velocidade com que eles são executados influenciam a percepção de tempo em imagens fixas ou em movimento. A edição também contribui como elemento temporal de uma sequência de imagens. Quanto mais rapidamente são executados os cortes, maior o ganho de velocidade percebida. Os tipos de transição entre as cenas escolhidas podem enfatizar um ritmo: fades (in, quando uma imagem aparece aos poucos, e out, quando uma cena some gradativamente) e fusões (quando uma cena mescla-se com outra, sendo que a primeira vai desaparecendo ao mesmo tempo que a posterior vai surgindo) são transições mais lentas, enquanto cortes-secos (hard-cut), mais bruscos.

Está claro que "o espaço, o tempo e a imagem devem entender-se como um todo" 9 " RÀFOLS \& COLOMER: 2006, p.29), mas não devemos esquecer que a temporalidade não se encontra somente no sonoro e no visual. $\mathrm{O}$ verbal inscreve $\mathrm{o}$ tempo em seu discurso, seja na descrição, na narração ou na dissertação.

[...] na linguagem audiovisual se articulam perfeitamente a língua e a música como sistemas de códigos complexos que se entrelaçam com as simulações perceptivas naturalistas características do desenho, da pintura, da fotografia, das montagens com imagem fixa e som, do cinema, do rádio, da televisão, etc., transferindo-lhe sua própria capacidade expressiva (RODRÍGUEZ: 2006, p.28)

\section{Conclusão}

O elemento distintivo de um designer gráfico de televisão é a habilidade de planejar e produzir imagens com som e movimento. Combinar texto, música e efeitos sonoros e depois sincronizá-los precisamente com as imagens, quadro a quadro, é a essência desse trabalho, e esta combinação provou ser das formas mais efetivas de ganhar a atenção ${ }^{10}$, (MERRITT, 1987, p.11)

\footnotetext{
8 “[...] timing is sensed by the eyes as well as by ears" [tradução livre da autora].

9 "El espacio, el tiempo y la imagen deben entenderse como un todo" [tradução livre da autora].

10 "The one distinctive element for the television graphic designer, is the ability to plan and produce images with sound and movement. Combining words, music and sound effects and then timing them precisely to pictures, frame-
} 
A identidade televisiva, ao representar os valores, as promessas e os conceitos de marca do canal, utiliza dos signos que o meio possibilita de forma a aumentar a eficácia da comunicação. Ao associarem-se às imagens sons e texto, esta interrelação reforça a mensagem, pois, sob a ótica da semiótica peirciana, podemos compreender o sucesso do uso de vários sentidos em um produto pelo maior acesso ao objeto que diferentes signos articulados podem estabelecer.

Essa constante ancoragem do signo em um objeto é o que possibilita uma coerência não só entre os diferentes signos de uma mesma peça de design - dos sonoros, visuais e verbais de uma mesma vinheta de identidade -, como também entre as diversas vinhetas de uma identidade televisiva mais completa. Sempre que os signos remeterem aos mesmos conceitos de marca, eles terão uma unidade entre si, pois estarão representando o mesmo objeto. Desta forma, eles poderão gerar significações coerentes com o objeto representado, sempre levando em consideração o repertório do público ao qual a identidade televisiva se destina.

O fato da identidade televisiva poder ser compreendida como um signo mais complexo possibilita o entendimento de que a combinação de signos das diferentes matrizes contribui para que o telespectador tenha maior acesso à marca do canal, numa relação que irá se estabelecer pelo hábito do uso. Por isso, concordamos com Santaella e Nöth (2005, p.69) quando afirmam que o código hegemônico deste século não está nem na imagem, nem na palavra oral ou escrita, mas nas suas interfaces, sobreposições e intercursos. Podemos acrescentar a estes signos também o som, que traz em si a dominância do tempo.

Analisamos, nas vinhetas interprogramas, como o verbal pode se interralacionar com o sonoro e o visual, como pode ocorrer o diálogo entre som e imagem e principalmente como o tempo pode se inscrever nas demais matrizes. Por isso, podemos concluir que a complexidade para a leitura da identidade televisiva deve-se ao fato de que ela constitui um signo cuja natureza semiótica não está só pautada na imagem, mas nas ligações indissolúveis do visual com o sonoro e o verbal.

\section{Referências bibliográficas}

ACKERMAN, Diane. Uma História Natural dos Sentidos. São Paulo: Bertrand Brasil, 1992.

by-frame, is the essence of the craft, and this combination has proved to be one of the most compulsive ways of gaining attention" [tradução livre da autora].

Caderno Seminal Digital Ano 16, nº 13, V. 13 (Jan.- Jun/2010) - ISSN 1806 -9142 
BAUMAN, Zygmunt. Vida para Consumo: a Transformação das Pessoas em Mercadorias. Rio de Janeiro: Jorge Zahar, 2008.

CHION, Michel. Audio-Vision: Sound on Screen. New York: Columbia University Press, 1994.

DONDIS, Donis A. Sintaxe da Linguagem Visual. 3. ed. São Paulo: Martins Fontes, 2007.

KRASNER, Jon. Motion Graphic Design \& Fine Art Animation: Principles and Practices. Oxford: Focal Press, 2004.

PEIRCE, Charles Sanders. The Collected Papers of Charles Sanders Peirce. Electronic edition. Virginia: Past Masters, 1994. Disponível em http://library.nlx.com/.

RÀFOLS, Rafael \& COLOMER, Antoni. Diseño Audiovisual. Barcelona: Gustavo Gili, 2006.

RODRÍGUEZ, Ángel. A Dimensão Sonora da Linguagem Audiovisual. São Paulo: Senac São Paulo, 2006.

SANTAELlA, Lucia. Matrizes da Linguagem do Pensamento: Sonora, Visual, Verbal. 1 ed. São Paulo: Iluminuras, 2005.

SANTAELLA, Lucia \& NÖTH, Winfried. Imagem: Cognição, Semiótica, Mídia. 4 ed. São Paulo: Iluminuras, 2005. 